\title{
Fine Mapping of Xa7, a Dominant Bacterial Blight Resistance Gene in Rice
}

\author{
Mekala Mallikarjun* and Anil S. Kotasthane \\ Department of Plant Pathology, College of Agriculture, Indira Gandhi Krishi \\ Vishwavidyalaya (IGKV), Raipur - 492012, Chhattisgarh, India
}

*Corresponding author

\begin{abstract}
A B S T R A C T
Bacterial blight (BB) caused by Xanthomonas oryzae pv. oryzae (Xoo) is a devastating disease in rice worldwide. The resistance gene Xa7, which provides dominant resistance against the pathogen with avirulence (Avr) gene AvrXa7, has proved to be durably resistant to BB. A set of SSR markers were selected from the "gramene" database based on the Xa7M5 gene initial mapping region on chromosome 6. This marker was used to construct a high-resolution genetic map of the chromosomal region surrounding the Xa7 gene. An F2 mapping population with 1300 highly susceptible individuals derived from a cross between the near isogenic lines (NILs) IRBB65 and Mahamaya were constructed to localize the $\mathrm{Xa} 7$ gene. $\mathrm{Xa} 7$ was previously located in a region between two markers M1 $(2.2 \mathrm{cM})$ and M3 $(0.5 \mathrm{cM})$ of chromosome 6 (Porter et al., 2003). Recently, Xa7 was further integrated to the region between two proximal markers GDSSR02 and RM20593, an interval of approximate $118.5 \mathrm{~kb}$ (Chen et al., 2008). Finally, the Xa7 gene was mapped to a $0.21-\mathrm{cM}$ interval between the markers GDSSR02 and RM20593. The Xa7-linked markers were landed on the reference sequence of $\mathrm{cv}$. Nipponbare through bioinformatics analysis. A contig map corresponding to the $\mathrm{Xa} 7$ gene was constructed. Candidate gene analysis of Xa7 revealed that the fourteen genes encode novel domains that have no amino acid sequence similar to other cloned Xa genes.
\end{abstract}

\section{Introduction}

Oryzae pv. oryzae (Xoo) is a limiting factor to rice yields in all major rice-growing regions of the world. Due to the fact that the bacterial pathogen is difficult to manage, the development of host plant resistance is considered as one of the most effective and economical means to control BB. For the sake of food security, application of variety resistance has been, and undoubtedly will continue to be, the major method of disease control for rice $\mathrm{BB}$. The rice-Xoo pathosystem has become the genetic model for understanding host-pathogen interactions and coevolution for cereals (Dai et al., 2007). In this host pathosystem, race-specific resistance shows the gene-for- gene relationship (Mew A clear understanding of the molecular mechanisms in host resistance to pathogens is the essential prerequisite for a better design of control strategies for rice BB (Dai et al., 2007). Large-scale and longterm cultivation of varieties carrying one single resistance gene resulted in a significant shift in pathogen race frequency with consequent breakdown of 
resistance in these cultivars. To tackle the problem of resistance breakdown, pyramiding of resistance genes into different varieties is indispensable. Identification and cloning of $\mathrm{BB}$ resistance genes has therefore become very important. During the last decade, significant achievements have been made in elucidating the molecular basis of ricepathogen interactions (Dai et al., 2007).Currently, more than $30 \mathrm{BB}$ resistance genes (R-genes) conferring host resistance against various strains of Xoo have been identified and designated with a series from Xa1 to xa31 (t) (Cheema et al., 2008). Genetical mapping of these $\mathrm{R}$ genes allows marker assisted breeding in rice. Xa7, a dominant resistance gene directed against Xoo, was originally identified in rice cv. DV85 (International Rice Research Institute accession number 8839) (Sidhu et al., 1978). A corresponding avirulence gene to $\mathrm{Xa7}$, avrXa7, has been cloned and identified as a member of the avrBs3 gene family (White et al., 2000). AvrXa7 is a virulence factor in strain PXO86 of Xoo, being targeted to plant cells by a type III secretion apparatus. This protein contains a functional nuclear localisation signal (NLS) and an acidic transcriptional activation domain motif for avirulence activity, indicating that its interaction with Xa7 might occur within the host nuclei (Yang et al., 2000). It has been proven that $\mathrm{Xa} 7$ would be a durable $\mathrm{R}$ gene because of a fitness penalty in Xoo associated with adaptation to Xa7 (Vera Cruz et al., 2000). The cloning of avrXa7 has greatly enhanced the understanding of the mechanisms in gene for- gene interactions, benefiting tagging of this resistance gene. Xa7 was previously located in a region between two markers M1 $(2.2 \mathrm{cM})$ and M3 $(0.5 \mathrm{cM})$ of chromosome 6 (Porter et al., 2003). Recently, $\mathrm{Xa} 7$ was further integrated to the region between two proximal markers GDSSR02 and RM20593, an interval of approximate 118.5 $\mathrm{kb}$ (Chen et al., 2008). The underlying objective of this study was to construct a highresolution map of the $\mathrm{Xa} 7$ gene, in an effort to clone it using the map-based cloning method. We have developed an F2 mapping population with 1300 individuals derived from the cross between the resistant parent IRBB65 and highly susceptible cv Mahamaya using Dhamtari isolate and have identified a great deal of SSR tightly linked markers of $\mathrm{Xa} 7$ and have constructed a BAC/PAC contig containing the target gene with overlapping clones, which will accelerate future markerassisted selection (MAS) breeding of Xa7.

\section{Materials and Methods}

The indica rice cv. IRBB65, which is the NIL with the $\mathrm{Xa} 7$ gene, was used as the donor parent, and crossed with the susceptible parent Mahamaya which is a non- Aus variety of isozyme group I which is cultivated in the plains of Chhattisgarh. Dhamtari isolate which is compatible with Mahamaya and incompatible with IRBB65 was selected to evaluate the resistance segregation of the F2 population derived from the cross between Mahamaya and IRBB65 by the leaf-clipping method (Kauffman et al., 1973). 80 lines experimental lines were used for the $\mathrm{Xa} 7$ Marker assisted selection breeding. BB resistance to Dhamtari isolate was evaluated by scissors-clipping three of the youngest leaves of each plant approximately $2 \mathrm{~cm}$ below the leaf tips with a bacterial suspension having $10^{9}$ cells $/ \mathrm{ml}$. The inoculum was prepared from bacteria revived from the stock maintained at $4^{\circ} \mathrm{c}$. The cultures were grown on the Walkimoto media for 3 days at $30^{\circ} \mathrm{c}$. The plants were scored as resistant or susceptible through the average lesion length which was measured for the three inoculated leaves after 20 days of inoculation (Kauffman et al., 1973). Leaf tissue of these plants was subjected to tissue lyser by following Modified CTAB protocol for DNA extraction from rice leaves of the uninoculated tissue, 
which was harvested at the time of bacterial blight inoculation. The controls used during inoculation were both parents of the F2 population.

\section{Candidate gene annotation}

According to the physical map of the target gene, the publicly available BAC or PAC sequences of $O$. sativa $\mathrm{cv}$. Nipponbare in the target gene region were downloaded from Rice Genome Sequence Program (RGP) web site (http://rgp.dna.affrc.go.jp/cgi-bin/ statusdb/) and Genbank (http://www.ncbi. nlm.nih.gov/Genbank/ index.html). The open reading frames (ORFs) and potential exon/intron boundaries were predicted for the sequences described above using FgenesH (http:// genomic.sanger.ac.uk), RiceGAAS (http://ricegaas dna.affrc.go.jp/), and GeneScan (http://genes.mit.edu/ GENSCAN) software. The candidate genes were analyzed through BLAST (http://www.ncbi.nlm.nih. gov/blast/Blast.cgi) and confirmed by the TIGR Rice Genome Annotation Version 5 (http://www.tigr. org/tigr-scripts/osal_web/ gbrowse/rice/).

\section{Results and Discussion}

\section{Genetic and physical map construction}

The parental lines $\mathrm{P} 1$ and the P2 plants, showed clear reactions to Dhamtari isolate. One of the parent of the F2 population, IRBB65 carrying Xa7, was resistant to pathogen Dhamtari isolate with an average lesion length of $0.50 \pm 0.17 \mathrm{~cm} 20$ days after inoculation. The other parent of the population, Mahamaya, was highly susceptible to Dhamtari isolate with an average lesion length of $24.6 \pm 2.62 \mathrm{~cm}$. The distribution of the lesion length for Dhamtari isolate inoculation in the $1300 \mathrm{~F} 2$ plants was bimodal with a valley at 5 to $6 \mathrm{~cm}$. Of the $\mathrm{F} 2$ progenies, segregation of resistant and susceptible plants fitted a 3:1 ratio which indicated that the resistance of IRBB65 to Dhamtari was controlled by a dominant resistance gene. Because the efficiency of mapping with a recessive class is two or three times higher than that with a random population per assayed plant (Zhang et al., 1994), a population consisting of 721 highly susceptible F2 individuals (with lesion length C $8.0 \mathrm{~cm}$ ) was selected for genetic mapping of the target gene.

\section{Genetic map of the Xa7 locus region}

Based on the preliminary mapping result of Xa7 (Porter et al., 2003), three publicly available BAC sequences of $O$. sativa $\mathrm{cv}$. Nipponbare, AP005610, AP006454 and AP006055, were downloaded from the RGP web site and Genbank in the gap between clone AP005192 and AP004989. For fine mapping of the Xa7 gene, thirty-two sets of SSR primers were adopted from the "gramene" database based on the above mentioned BAC clones for parents polymorphism assay. Sequence matching by bioinformatic analysis showed that (Figure 1) L655 found on the BAC clone P0485A07, C52865S on OSJNBa0032M14, C11635S on B1153E06 and P0710B08, C259C on P0547F09, E3288S on P0547F09. Our analysis showed that the physical distance between L655 and E3288S was 3 Centimorgans.

\section{Candidate gene analysis for $\mathrm{Xa}$}

A contig map covering the $X a 7$ region is flanked by L655 and E3288S accounting for a physical contig map covering $633 \mathrm{~kb}$ region 6,33,632 bases. L655 and E3288S anchored to the BAC clone P0485A07and P0547F09 respectively. The contig map covered five BAC / PAC clones, P0485A07, OSJNBa0032M14, P0710B08, P0547F09 and P0547F09. As shown in the Table 1. 


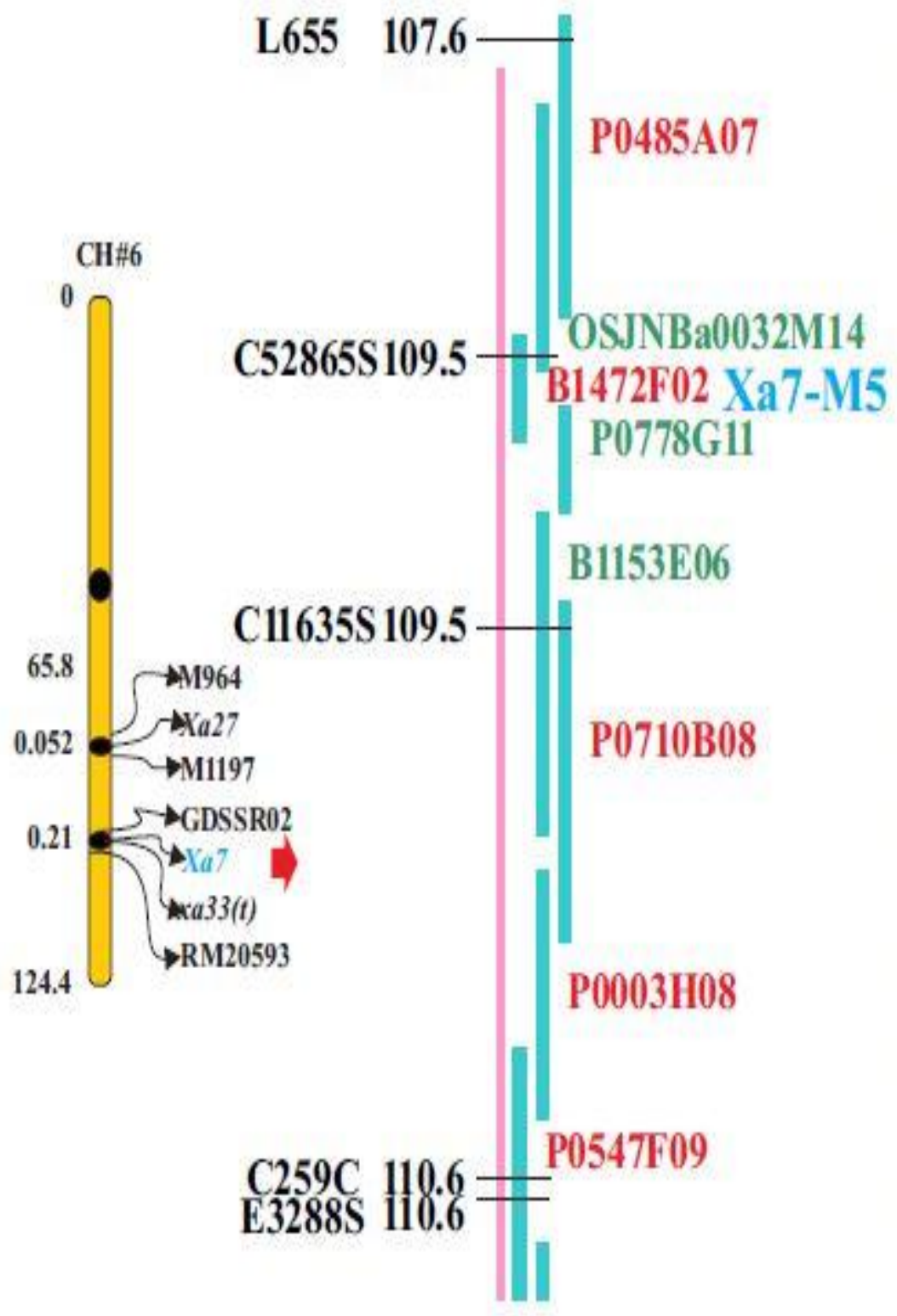

Table.1 Correlative in-silico mapping and blast analysis and landing of L655, C52865S, C11635S, C259C and E3288S a physical positions on BAC / PAC clones

\begin{tabular}{|c|}
\hline Marker \\
\hline L655 \\
\hline C52865S \\
\hline C11635S \\
\hline C259C \\
\hline E3288S \\
\hline
\end{tabular}

\begin{tabular}{|c|}
\hline Anchored BAC/PAC clone \\
\hline P0485A07 \\
\hline OSJNBa0032M14 \\
\hline P0710B08 \\
\hline P0547F09 \\
\hline P0547F09 \\
\hline
\end{tabular}


Table. 2 Genes on sequences spanning between the RFLP markers L655 $=27780655$ To 27780304 and E3288S = 28414048 to $28414287(28414287-27780655=633632$ bases apart $)$ encompassing $\mathrm{Xa7gene}$

\begin{tabular}{|c|c|c|}
\hline \multicolumn{2}{|c|}{ BAC/PAC clone } & Putative Gene Functions \\
\hline 1. & Os06g0670400 & Similar to CYP59 (CYCLOPHILIN 59 \\
\hline 2. & Os06g0670500 & Similar to Multidomain cyclophilin type peptidyl-prolyl cis-trans isomerase. \\
\hline 3. & Os06g0670633 & Similar to embryo-sac basal-endosperm layer embryo-surrounding-region. \\
\hline 4. & Os06g0671000 & Similar to Potassium transporter 1 (AtPOT1) (AtKUP1) (AtKT1). \\
\hline 5. & Os06g0671150 & Auxin responsive SAUR protein family protein. \\
\hline 6. & Os06g0671300 & Cytochrome P450 family protein. \\
\hline 7. & Os06g0671600 & Beta tubulin $\% 2 \mathrm{C}$ autoregulation binding site domain containing protein. \\
\hline 8. & Os06g0671700 & Similar to toprim domain-containing protein. \\
\hline 9. & Os06g0671800 & Similar to patellin-5. \\
\hline 10. & Os06g0671900 & Similar to Tubulin beta-3 chain. \\
\hline 11. & Os06g0672400 & Protein of unknown function DUF640 domain containing protein. \\
\hline 12. & Os06g0673500 & Similar to polyubiquitin containing 7 ubiquitin monomers. \\
\hline 13. & Os06g0675600 & Similar to GRAB2 protein. \\
\hline 14. & Os06g0675700 & Similar to High pI alpha-glucosidase. \\
\hline 15. & Os06g0675900 & Similar to High pI alpha-glucosidase. \\
\hline 16. & Os06g0676000 & Similar to Integral membrane protein OsNramp3 (Fragment). \\
\hline 17. & Os06g0676600 & Protein kinase $\% 2 \mathrm{C}$ core domain containing protein. \\
\hline 18. & Os06g0676700 & Similar to High pI alpha-glucosidase. \\
\hline 19. & Os06g0677300 & Zinc finger\%2C RING/FYVE/PHD-type domain containing protein. \\
\hline 20. & Os06g0677400 & 3-hydroxyisobutyrate dehydrogenase domain containing protein. \\
\hline 21. & Os06g0677500 & Protein prenyltransferase domain containing protein. \\
\hline 22. & Os06g0677600 & Like-Sm ribonucleoprotein $\% 2 \mathrm{C}$ core family protein. \\
\hline 23. & Os06g0677700 & YT521-B-like protein family protein. \\
\hline 24. & Os06g0677800 & Similar to P-167-1_1 (Fragment). \\
\hline 25. & Os06g0678200 & Similar to Geranyl diphosphate synthase. \\
\hline 26. & Os06g0678650 & WD40 repeat-like domain containing protein. \\
\hline 27. & Os06g0678651 & Similar to WD-40 repeat family protein \\
\hline 28. & Os06g0678800 & Similar to Pollen-specific protein NTP303 precursor. \\
\hline 29. & Os06g0679100 & Similar to Anaphase-promoting complex subunit 8-like protein. \\
\hline 30. & Os06g0679400 & Similar to Myb-related protein Pp2. \\
\hline 31. & Os06g0679500 & Similar to Avr9 elicitor response-like protein. \\
\hline 32. & Os06g0679800 & Heat shock protein Hsp70 domain containing protein. \\
\hline 33. & Os06g0680500 & Similar to Glutamate receptor 3.4 precursor (Ligand-gated ion channel 3.4) \\
\hline 34. & Os06g0680700 & Cytochrome P450 family protein. \\
\hline 35. & Os06g0680900 & Similar to predicted protein. \\
\hline 36. & Os06g0681200 & Cupredoxin domain containing protein. \\
\hline 37. & Os06g0681600 & Heam peroxidase family protein. \\
\hline 38. & Os06g0681700 & Protein of unknown function DUF6\%2C transmembrane domain containing protein \\
\hline
\end{tabular}

The high resolution molecular marker map of genomic location encompassing $\mathrm{Xa} 7$ generated in the present investigation represents anchored 5 RFLP markers, 54 BAC / PAC Clone derived SSR markers, 22 previously known RM series markers (www.gramene.org). The high resolution molecular marker map of genomic location encompassing $\mathrm{Xa} 7$ can provide high levels of polymorphism needed to follow genomic segments through the narrow crosses and closely related pedigrees of a rice breeding 
program. Proteins of these genes (Table 2) have several modules or domains, each of which has a distinct evolutionary origin and function. Five conserved domains of predicted candidate genes, DUF640, Ubiquitin, NAM protein, Glyco_hydro_31 and PRK00701 were searched from NCBI's Conserved Domain Database (http://www.ncbi.nlm.nih.gov/Structure/cdd/c dd.shtml) The DUF640 family represents a conserved region found in plant proteins including resistance protein-like protein (Y. Zhang et al., 2009) The ubiquitin superfamily is a rich repository of small, conserved, functionally unique, and important proteins, and its members have been implicated in numerous cancers, neurodegenerations, inflammations, and various disorders affecting signal transduction or protein halflife (Larsen and Wang 2002). Glycosyl hydrolases are key enzymes of carbohydrate metabolism; glycosyl hydrolases family 31 comprises enzymes that are, or similar to, alpha-galactosidases (Henrissat, 1998) PRK00701, manganese transport protein $\mathrm{MntH}$, is a member of family NRAMPs (natural resistance-associated macrophage proteins) (Zhang et al., 2009) NRAMPs have been characterised in mammals as divalent transition metal transporters involved in iron metabolism and host resistance to certain pathogens (Nelson, 1999). No apical meristem (NAM) proteins are plant development proteins.

Much evidence has indicated that $\mathrm{Xa} 7$ is a broad spectrum and durable resistance gene. Rice lines with Xa7 prevented bacterial blight epidemics with the presence of virulent Xoo strains in the Philippines from 1993 to 1995 (Vera Cruz et al., 2000). Utilization of the horizontal resistance genes is more significant than use of the vertical resistance genes in genes pyramiding. Because the horizontal resistance gene $\mathrm{Xa} 7$ has not been used in MAS breeding in South China, the Xa7 gene can be pyramided into elite varieties combined with other BB resistance genes. As by-products of our fine mapping, a number of tightly linked markers for the Xa7 gene had been developed; these could provide a useful tool for the marker-assisted transfer of this $\mathrm{R}$ gene in rice improvement programs. Five markers (L655, C52865S, C11635S, C259C, E3288S) tightly linked to $\mathrm{Xa} 7$ (genetic distancel3 centi morgans) and the distance from L655, C52865S 2 centimorgans is can be used in MAS breeding. Because of their much tighter linkages or co-segregation with Xa7 than the previous markers (M1-M5), more convenient operation than for the AFLP-based markers (M1-M5), and high level of polymorphism in rice germplasm.

\section{Acknowledgments}

This work was supported by the Molecular Plant Pathology Laboratory of Department of Plant Molecular Biology and Biotechnology, CoA, IGKV Raipur. We thank Dr. A.S. Kotasthane and Dr. Toshy Agarwal for their Assistance and Suggestions

\section{References}

Cheema, K. K., Grewal, N. K., Vikal, Y., Sharma, R., Lore, J. S., Das, A. et al., (2008). A novel bacterial blight resistance gene from Oryza nivara mapped to $38 \mathrm{~kb}$ region on chromosome 4L and transferred to Oryza sativa $\mathrm{L}$. Genetics Research, 90, 397-407.

Chen, S., Huang, Z. H., Zeng, L. X., Yang, J. Y., Liu, Q. G., and Zhu, X. Y. (2008). High-resolution mapping and gene prediction of Xanthomonas oryzae pv. oryzae resistance gene Xa7. Molecular Breeding, 22, 433-441. doi: 10.1007/ s11032-008-9187-1.

Dai LY, Liu XL, Xiao YH, Wang GL (2007) Recent advances in cloning and characterization of disease resistance 
genes in rice. $\mathrm{J}$ Integr Plant Biol 49:112-119.

Kauffman, H. E., Reddy, A. P. K., Hsieh, S. P. Y., and Merca, S. D. (1973). An improved technique for evaluating resistance of rice varieties to Xanthomonas oryzae pv. oryzae. Plant Disease Report, 57, 537-541.

Larsen, C. N., and Wang, H. (2002). The ubiquitin superfamily: members, features, and phylogenies. Journal of Proteome Research, 5, 411-419. doi:10.1021/pr025522n Henrissat, B. (1998). Glycosidase families. Biochemical Society Transactions, 26, 153-156.

Porter, B. W., Chittoor, J. M., Yano, M., Sasaki, T., and White, F. F. (2003). Development and mapping linked to the rice bacterial blight resistance gene Xa7. Crop Science, 43, 1484-1492.

Sidhu GS, Khush GS, Mew TW (1978) Genetic analysis of bacterial blight resistance in seventy-four cultivars of rice, Oryza sativa L. Theor Appl Genet 53:105-111

Vera Cruz CM, Bai JF, Ona I, Leung H, Nelson RJ, Mew TW, Leach JE (2000) Predicting durability of a disease resistance gene based on an assessment of the fitness loss and epidemiological consequences of avirulence gene

White, F. F., Yang, B., and Johnson, L. B. (2000). Prospects for understanding avirulence gene function. Current Opinion in Plant Biology, 3, 291-298. doi:10.1016/S1369-5266 (00)00082-0.

Yang, B., Zhu, W., Johnson, L. B., and White, F. F. (2000). The virulence factor AvrXa7 of Xanthomonas oryzae pv. oryzae.

Zhang Q, Lin SC, Zhao BY, Wang CL, Yang WC, Zhou YL, Li DY, Chen CB, Zhu LH (1998) Identification and tagging a new gene for resistance to bacterial blight (Xanthomonas oryzae pv. oryzae) from O. ruWpogon. Rice Genet Newsl 15:138-142.

\section{How to cite this article:}

Mekala Mallikarjun and Anil S. Kotasthane. 2018. Fine Mapping of Xa7, a Dominant Bacterial Blight Resistance Gene in Rice. Int.J.Curr.Microbiol.App.Sci. 7(02): 3281-3287. doi: https://doi.org/10.20546/ijcmas.2018.702.394 